\title{
BEHAVIORAL EVIDENCE OF EVERYDAY SADISM IN A NOVEL SAMPLE OF CHILEAN STUDENTS.
}

\author{
Paulina Córdova, Jorge Delgado and Ana María Fernández
}

Laboratory of Evolution and Interpersonal Relationships (LERI), Universidad de Santiago, Santiago, Chile

paulina.cordova@usach.cl

\begin{abstract}
This study evaluates the behavioural correlates of everyday sadism using Internet material that is commonly available in varied forms. We selected games, images, and videos that best reflected the dimensions of verbal, physical, and vicarious everyday sadism of the Comprehensive Evaluation of Sadistic Trends (CAST). Our participants were 35 students who received the experimental stimuli at the laboratory and completed convergent instruments, such as the Dark Triad and Interpersonal Reactivity Index. We found that the expected correlations with everyday sadism were positively associated with the liking and amusement of cruel games and videos, which was significant for the verbal and vicarious dimensions, and sadism was the only significant predictor of the experimental stimuli. We discuss how a prosocial human adaptation might be potentiated by the enjoyment of not so positive interactions in the virtual environments of social networks, which might help in understanding Facebook trolling or similar phenomena.
\end{abstract}

Keywords: Dark Triad, Everyday Sadism, Empathy, Dark Tetrad. 


\section{INTRODUCTION}

Gregarious species have an interactive repertoire of prosocial behaviors evidenced by the work of human ethology (Eibl Eibesfeldt, 1979), comparative observations in primatology (Behncke, 2015), and psychology (see the Social Brain Hypothesis in Dunbar \& Shultz, 2007), just to name a few examples. However, this propensity for prosociality also provides opportunities for antisocial, competitive or manipulative behavior in our species to emerge (i.e., intrasexual competition, outgroup aggression, Buss, 2016).

Our human nature is full of examples of innate affiliative motivations in the form of mother-infant attachment early on life (Bowlby, 1982), to the development of friendships and social networks later in adolescence and adulthood (Barakzai \& Shaw, 2018; Krems, 2018; Tooby \& Cosmides, 1996). But this predisposition to favor sociality and the company of others might also motivate the development of not so auspicious individual traits, such as the Dark Tetrad of Personality (Buckels, Jones \& Paulhus, 2013). This collection of four negative subclinical traits includes the classical dark triad of personality (Paulhus \& Williams, 2002): which characterizes individuals with a tendency to manipulate others for their personal advantage (Machiavellianism), the feeling of entitlement, being more special than others (narcissism), and an exaggerated lack of empathy (psychopathy). More recently, the dark tetrad came together by the addition of the enjoyment of cruelty and finding pleasure in other's suffering, in the form of everyday sadism (Buckels et al., 2013). In their study, Wai and Tiliopoulos (2012) found that subjects with dark triad profiles exhibit a high desensitization towards the negative emotions of others, which in turn is increased by an intact cognitive empathy that helps their cruel and manipulative nature.

Buckels (2012) indicates that the phenomenon called "Schadenfreude" is a good starting point to begin investigating everyday sadism. Schadenfreude is a German concept that refers to the experience of pleasure in the misfortune of another (Feather \& Nairn, 2005), and it can happen when we obtain enjoyment from the conception that the person deserves to be punished (there is talk of a symmetry of the act and later misfortune), and it can also be the result of envy (Smith, Powell, Combs \& Schurtz, 2009). Despite the above, Buckles (2012) differentiates schadenfreude from everyday sadism, since schadenfreude often has its basis in the sense of justice that the sadist lacks, which makes enjoyable causing harm to another and deliberately humiliating in order to affirm dominance or simply for the pleasure that it produces (Buckels et al., 2013).

The human natural tendency to favor sociality and interaction with others has caused the explosion of the Internet and social media, which have quickly come to characterize our way of living (Dunbar \& Shultz, 2007; Sherman, Hernandez, Greenfield, \& Dapretto, 2018). Today, people are constantly exposed to relevant social information through technology (Waytz \& Gray, 2018), as well as to violent movies, brutal sports, and bloody video games, which build on our motivation and affinity for pleasurable social observation (Barkow, 1992; Kircaburun et al., 2018). Buckels et al. (2013) proposed that the popularity of cruel commonplace activities derives from a subclinical form of everyday sadism, which is a broader category of sadism resulting from the widespread favoring of cruelty, violence, and brutality in the media. Greitemeyer (2017) found that high levels of everyday sadism correlate with the hours devoted to violent video games. 
Similarly, Van Geel, Goemans, Toprak and Vedder (2016) wanted to analyze whether the Big Five, the dark triad, and sadism predict traditional bullying and cyberbullying. These authors found that both psychopathy and sadism were strongly related to traditional bullying, and overall sadism would turn out to be a predictor of antisocial behaviors, such as harassment and cyberbullying.

In this investigation, we sought to provide behavioral evidence that the enjoyment of cruelty and the pleasure derived out of cost inflicting and violence observation in virtual environments might be measured and characteristic of everyday sadism in a novel population of Chilean students. Our objective is to evaluate the empirical validity of the Comprehensive Evaluation of Sadistic Trends (CAST), which contemplates the different aspects of everyday sadism: direct physical sadism, direct verbal sadism, and vicarious sadism. To test empirically the CAST and its convergence with actual behavior, we selected game material and video images freely available on the Internet, and we tested the correlation of increasing liking and enjoyment of the "sadistic" virtual stimuli with the average scores obtained in the dimensions of everyday sadism.

\section{METHODS}

A quasi-experimental study incorporated 35 students of both sexes (62.9\% women and $37.1 \%$ men) from different schools (majors) at Universidad de Santiago de Chile. The inclusion criteria were: to be over 18-years-old and not to have been diagnosed with a personality disorder. We discarded the data of five participants; one participant who presented an exclusion criterion, one participant that presented instrumental difficulties, and three participants who requested to be discarded after debriefing. Therefore, the final sample size was 30 participants ( $56.7 \%$ women and $43.3 \%$ men), who came voluntarily to the experiment and were given a chocolate bar as an incentive for participation.

\section{Instruments}

Short Dark Triad (SD3)

The SD3 was developed by Jones and Paulhus (2014) and adapted to Chile by Baeza and Fernández (2019), following the method of back translation and the recommendations of Muñiz, Elousa and Hambleton (2013). The SD3 consists of 27 items divided into three subscales of 9 questions scored from 1 to 4, measuring each feature of the dark triad: narcissism (i.e., "group activities are rather boring for me"), Machiavellianism (i.e., "I like to use deception to get what I want"), and subclinical psychopathy (i.e., "I enjoy taking revenge from powerful figures"). The reliability for this investigation was: Machiavellianism Cronbach $\alpha=0.76$; Psychopathy $\alpha=0.73$ and Narcissism $\alpha=0.65$.

Interpersonal Reactivity Index (IRI)

Is a measure of empathy created by Davis (1980) and adapted to Chile by Fernández, Dufey, and Kramp (2011). Four dimensions underlying empathy are assessed: Fantasy 
(FS), Perspective Taking (PT), Empathic Concern (EC), and Personal Distress (PD). The reliability of the scale obtained in our sample was: FS $\alpha=0.79, \mathrm{EC} \alpha=0.71, \mathrm{PT} \alpha=$ 0.74 and PD $\alpha=0.75$.

\section{Comprehensive Evaluation of Sadistic Trends (CAST)}

The CAST was developed by Buckels and Paulhus (2014) and consists of 18 items, two of which are distractors. To adapt it to our sociocultural context, a translation was carried out, followed by a back translation by people with personality training and competent in both English and Spanish (Muñiz \& Fonseca-Pedrero, 2019). The CAST measures three varieties of sadistic tendencies on a scale from 1 to 7 : direct physical, direct verbal, and vicarious sadism. In this study, a Cronbach alpha of 0.86 was found: $\alpha=0.77$ for the direct-verbal dimension, $\alpha=0.63$ for the direct-physical dimension, and $\alpha=0.81$ for the vicarious dimension.

\section{Materials}

Participants used personal computers with the Windows 7 operating system and the portable GOM PLAYER program, in which the game "The frog in the blender" with an extension of "swf" was executed. The file formats were: Windows Media Player "mp4" format and Windows Image Viewer for "jpg" format.

\section{Experimental Stimulus}

The different dimensions of everyday sadism were portrayed in videos and games that reflected this psychological tendency, according to the criteria of the research team and the definitions provided in the CAST dimensions. Direct physical sadism incorporated the GOM player program in its portable version to play the game "the frog in the blender". The file was dragged to the player, where you can interact with ten buttons, which appear on the screen and are controlled with the computer mouse, portraying a slowly "liquefying frog" in caricature format. Then, the target questions asked: "How fun do you find the game?" answered on a Likert scale from 1 (not fun at all) to 5 (extremely fun). Vicarious sadism was assessed by a compilation of "game over" screens edited by the researchers, projected onto video screens in which the characters died in multiple ways. The target question posed: "How trivial did you find the content of the game?", and it was answered on a Likert scale from 1 (seems very unusual) to 5 (I see it daily, is very common). A compilation of video routines from the television program "Jackass" was also used, showing humorous scenes of the protagonists where they perform unnecessarily risky, dangerous, and painful activities to amuse the audience. Participants saw the material and answered "How funny is the content of the video?" on a Likert scale from one 1 (very boring) to 5 (very funny). Finally, for the direct verbal dimension, a video of "practical jokes" showing different jokes made by a YouTuber on strangers, was followed by a question of "How funny did you find the content of the video?" on a Likert scale from one 1 (very boring) to 5 (very funny). 


\section{Procedure}

The study was approved by our institutional review board (Ethics Committee of the university). Participants were invited to the lab, and they signed the first informed consent that masked the real objective of the experimental task stating that "we wanted to know their taste for the material that circulates on the Internet, and to correlate them with their personality factors". Nevertheless, the real objective of the study was reported individually to all participants at the end of the study (empirically validating a measure of everyday sadism). Participants were debriefed at the end of the experiment and were given the option to delete data collected without their full informed consent at the beginning of the study (three participants requested this option). Participation was collective with a maximum of 12 people coming to a laboratory room with computers simultaneously. After signing the initial consent, participants completed demographic questions (age, gender, psychological diagnoses, and ongoing health or psychological treatments) and the instruments. First, they played "The frog in the blender" and answered the corresponding question, and then followed the rest of the experimental stimuli and their respective questions. The participants used headphones during the procedure to listen privately to the experimental stimuli and avoid being influenced by others' reactions to the games and videos (Figure 1).
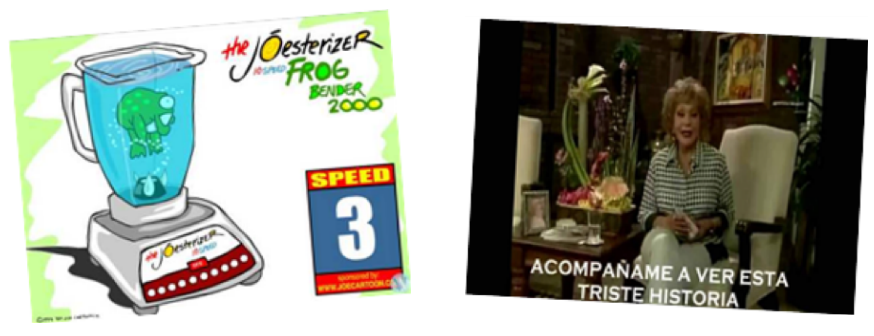

Note: The picture on the left represents the Frog in the Blender stimuli, with the speed of the blender at number 3. The picture on the right portraits the introduction to the practical jokes on people, introduced with Spanish subtitles.

Figure 1: Sample experimental stimuli.

\section{Data analysis}

We conducted Pearson correlations between the experimental stimulus responses and the CAST, dark triad, and empathy measures. Second, we ran multiple regressions and then a stepwise regression to test the instrumental validity of the CAST entering as predictors the dark triad and empathy dimensions on the total score of the CAST. Finally, we re-ran the multiple and stepwise regression to predict the behavioral stimulus responses from the dark triad and the CAST dimensions. 


\section{RESULTS}

In Table 1 we present all the descriptive statistics of the measures used in the study.

Table 1: Mean and standard deviations of the SD3, CAST, IRI and the experimental stimuli.

\begin{tabular}{lcc}
\hline Variable & Mean & SD \\
\hline Everyday sadism & 2.31 & .96 \\
Direct physical sadism & 1.89 & .88 \\
Direct verbal sadism & 2.95 & 1.37 \\
Vicarious sadism & 2.11 & 1.15 \\
Machiavellianism & 2.61 & .68 \\
Psychopathy & 2.21 & .63 \\
Narcissism & 2.49 & .60 \\
FS & 3.62 & .83 \\
PT & 3.74 & .67 \\
EC & 3.76 & .66 \\
PD & 2.94 & .75 \\
Experimental stimuli & 2.10 & 1.08 \\
\hline Note: Fntasy & & \\
\hline
\end{tabular}

Note: Fantasy (FS), Perspective Taking (PT), Empathic Concern (EC) and Personal Distress (PD).

We created a composite of the experimental stimuli responses (game and the videos), which had a positive moderate and significant correlation with the CAST. More specifically, direct physical sadism and the behavioral stimuli had a low positive significant correlation, and the vicarious dimension had a positive and moderate to high correlation with the behavioral tasks. Also, the behavioral stimulus presented a clear tendency to associate directly with the dark triad components; and it tended to correlate negatively with two dimensions of empathy (Table 2). 
Table 2: Pearson correlations between the experimental stimuli and the different dimensions assessed.

\begin{tabular}{|c|c|c|c|c|c|c|c|c|c|c|c|}
\hline Variable & 2 & 3 & 4 & 5 & 6 & 7 & 8 & 9 & 10 & 11 & 12 \\
\hline 1. Experimental stimuli & $.50^{* *}$ & $.52^{* *}$ & $.39^{* *}$ & .35 & .35 & .32 & .25 & -.27 & -.31 & .01 & -.22 \\
\hline 2. Everyday sadism & & $.84^{* *}$ & $.83^{* *}$ & $.85^{* *}$ & $.68^{* *}$ & $.54^{* *}$ & .10 & $-.42^{* *}$ & $-.40^{*}$ & -.13 & -.33 \\
\hline 3. Vicarious sadism & & & $.62^{* *}$ & $.51^{* *}$ & $.45^{*}$ & $.41^{*}$ & -.07 & -.31 & -.30 & -.14 & -.26 \\
\hline 4. Direct physical sadism & & & & $.57^{* *}$ & $.66^{* *}$ & .34 & .28 & -.21 & -.35 & -.17 & $-.44^{*}$ \\
\hline 5. Direct verbal sadism & & & & & $.61^{* *}$ & $.57^{* *}$ & .09 & $-.51^{* *}$ & $-.36^{* *}$ & -.06 & -.19 \\
\hline 6. Machiavellianism & & & & & & $.47^{* *}$ & .27 & $-.38^{*}$ & -.26 & -.05 & -.22 \\
\hline 7. Psychopathy & & & & & & & -.21 & $-.59^{* *}$ & $-.43^{* *}$ & -.05 & -.24 \\
\hline 8. Narcissism & & & & & & & & -.05 & .04 & .31 & -.02 \\
\hline 9. Empathic concern & & & & & & & & & $.36^{*}$ & $.42^{*}$ & .22 \\
\hline 10. Perspective taking & & & & & & & & & & .06 & .03 \\
\hline 11. Fantasy & & & & & & & & & & & $.51^{* *}$ \\
\hline 12. Personal distress & & & & & & & & & & & $1.00^{* *}$ \\
\hline
\end{tabular}

Note: ${ }^{* *}$ The correlation is significant at the 0.01 level (bilateral). ${ }^{*}$ The correlation is significant at the 0.05 level (bilateral).

The results of a stepwise regression, to evaluate the predictive validity of the scores on the CAST from the dark triad components and the experimental stimulus yielded Machiavellianism $(\beta=.51, \mathrm{t}=3.34, p=0.002)$ and the experimental stimuli composite $(\beta=0.29, \mathrm{t}=2.09, p=0.047)$ as significant predictors of everyday sadism (Adjusted $R^{2}=$ $\left.0.54, F_{(4,29)}=9.54, p=0.000\right)$.

Finally, to evaluate if the behavioral stimuli was predicted from the independent CAST dimensions, we found that only vicarious sadism was a significant predictor $(\beta=$ $0.53)$, but when we entered all the dimensions and the total scores as predictors on a stepwise regression, only the CAST $(\beta=0.55, \mathrm{t}=3.45, p=0.002)$ was a significant predictor (Adjusted $R^{2}=0.27, F_{(1,29)}=11.92, p=0.002$ ) (Figure 2). 


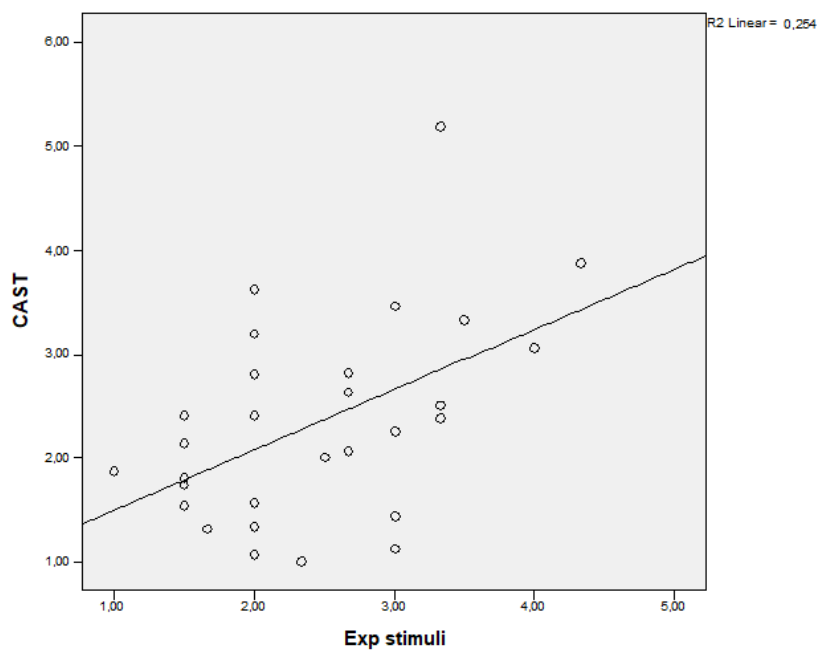

Figure 2: Association of the experimental stimuli with everyday sadism.

\section{DISCUSSION}

In this study, we provide convergent validity of everyday sadism with behavioral stimuli normally found on the Internet in a novel population of Chilean students. Similarly, we found a direct association between everyday sadism, the dark triad components of psychopathy, and Machiavellianism, and an inverse correlation of everyday sadism with empathic concern and perspective taking.

The experimental stimuli had a direct association with Machiavellianism and psychopathy. So, it is possible that sadism provides difficulties in feeling remorse and concern for others. Similarly, it is consistent with the fact that the only dimension of the CAST that explains the most variance in the experimental task was vicarious sadism. Everyday sadism, Machiavellianism, and psychopathy are characteristics that could be manifested on the Internet or social networks since it is a context which congregates a large number of people from which to take advantage of (Kircaburun, Demetrovics \& Tosuntas, 2018). Also, current studies provide evidence that everyday sadists are attracted to violent games as they allow them to satisfy an increased enjoyment of cruelty, providing emotional benefits (Greitemeyer, Weiß \& Heubergermes, 2018).

As we mentioned initially, the human tendency to favor sociality might be the basis for sadism, as well as the dark triad components to prosper, which are relevant to the exploitation of others. In the profile of psychopathy, there is insensibility and behavior without remorse; in the profile of Machiavellianism there is manipulation; and in everyday sadism there are behaviors associated with the pleasure of observing or indirectly inflicting physical or psychological harm on virtual games or discussions with others (Jones \& Paulhus, 2011; Porter \& Woodworth, 2006; Buckels et al., 2013). So that individuals with these traits look for satisfying their own needs and obtaining some benefit from social interactions with others, which is particularly associated with everyday sadism. The low relationship of everyday sadism with narcissism could be because this profile seeks admiration and the attention of others (Campbell \& Miller, 2011), but does not focus on the provocation and harming others.

The human propensity for prosociality can also encourage negative inclinations and seemingly antisocial traits, since these profiles also convey a greater reproductive 
opportunity, increasing the fitness of whom may be socially exploitative by facilitating success in fighting and hunting (Nell, 2006 in Buckels, Trapnell, Andjelovic, \& Paulhus, 2018). As a result, humans evolved a motivational architecture and brain activity to reinforce such behaviors in virtual environments, such as the Internet (Sherman, Hernandez, Greenfield, \& Dapretto, 2018).

Similarly, the negative association between two dimensions of empathy and everyday sadism is in line with the literature, because the dimension of empathic concern involves experiencing feelings of compassion and sympathy for the misfortune of others, and perspective taking measures the ability to adopt the perspective of others. On the contrary, everyday sadism involves obtaining some emotional benefit by causing or simply observing the suffering of others; therefore, having less empathy might have a decreasing effect of the discomfort generated by others misfortune.

Our findings are consistent with how everyday sadism could, for example, appear on the Internet through certain behaviors, such as Facebook trolling (Buckels, Trapnell \& Paulhus, 2014; Craker \& March 2016). This could be expressed through the publication of comments aimed at creating conflicts in the victims or objectives, generating discomfort, and encouraging others to respond with personal attacks. Fitting into the dimension of verbal sadism, since it does not refer to direct physical aggression but mainly words that may be offensive to some users and the conditions provided by anonymity (allowing to say what you want without the consequences that arise in other real contexts; Suler, 2004). At the same time, there is coherence with what is added by the vicarious dimension, since it is a behavior that, after being carried out, implies a pleasant contemplation of the effects that comments have on others. This can be transferred to the experiential area of daily life, which implies the enjoyment of elements that can be found in our current society, such as violent movies, brutal sports or video games with cruel content (Buckels, 2013).

Among the limitations of our study, the reduced sample size of this pilot study greatly affects the generalizability of the results. Similarly, the low consistency of the direct physical sadism dimension might have obscured any correlation with the behavioral stimulus, but we cannot determine that from our current sample.

To conclude, with increasing access to the Internet, everyday sadism can satisfy the appetite for cruelty and damaging observation in virtual contexts. This combination of (heightened) appetitive and (diminished) avoidance processes might help explain the emergence of online trolling behavior (Buckels, Trapnell, Andjelovic, \& Paulhus, 2018). This could be taken as a process favored by our adaptive prosociality into this new virtual space (Klimovsky, 1997; Sherman et al., 2018). Within a framework of sociability, the continuous interaction with these less desirable personality traits can be considered a byproduct of our gregarious nature, since it reports benefits at the expense of others in an anonymous environment (Jonason, Duineveld \& Middleton, 2015), while the prosociality involved in empathic tendencies has been recently found to be associated with peer support and defending in online as well as real contexts (Lambe, Cioppa, Hong, \& Craig, 2018). 


\section{ACKNOWLEDGMENTS}

This research was supported by Fondo Nacional de Desarrollo Científico y Tecnológico of the Government of Chile: Fondecyt Grants \#1181114 and \# 1170513.

\section{REFERENCES}

Baeza, C., \& Fernández, A. (2019). Adaptación de la escala de Triada Oscura de la Personalidad (SD3) al contexto chileno [Adaptation of the Dark Triad Scale to the Chilean context). Manuscript in preparation.

Barakzai, A., \& Shaw, A. (2018). Friends without benefits: When we react negatively to helpful and generous friends. Evolution and Human Behavior, 39(5), 529-537. DOI

Barkow, J. H. (1992). Beneath new culture is old psychology: Gossip and social stratification. In J. H. Barkow, L. Cosmides, \& J. Tooby (Eds.), The adapted mind: Evolutionary psychology and the generation of culture (pp. 627-637). New York, NY, US: Oxford University Press.

Behncke, I. (2015). Play in the Peter Pan ape. Current Biology, 25(1), 24-27. DOI

Bowlby, J. (1982). Attachment and loss. Vol. 1: Attachment (2nd ed.). New York: Basic Books.

Buss, D. M. (Ed.) (2016). The Handbook of Evolutionary Psychology (second edition). Hoboken, NJ: Wiley.

Buckels, E. E. (2018). The psychology of everyday sadism (T). University of British Columbia. Retrieved from https://open.library.ubc.ca/collections/ubctheses/24/items/ 1.0369056

Buckels, E., Jones, D. \& Paulhus, D. (2013). Behavioral confirmation of everyday sadism. Psychological Science, 24(11), 2201-2209. DOI

Buckels, E. \& Paulhus, D. (2013). Comprehensive assessment of sadistic tendencies (CAST). Unpublished measure, University of British Columbia

Buckels, E., Trapnell, P., Andjelovic, T., \& Paulhus, D. (2018). Internet trolling and everyday sadism: Parallel effects on pain perception and moral judgment. Journal of Personality. 2018;000:1-13. DOI

Buckels, E., Trapnell, P. \& Paulhus, D. (2014). Trolls just want to have fun. Personality and Individual Differences, 67, 97-102. DOI

Campbell, B. \& Miller, J. (2011). The handbook of Narcissism and Narcissistic personality disorder: Theoretical Approaches, Empirical Findings, and Treatments. New Jersey: Wiley \& Sons. $\underline{\mathrm{DOI}}$

Craker, N. \& March, E. (2016). The dark side of Facebook: The Dark Tetrad, negative social potency, and Trolling behaviours. Personality and Individual Differences, 102, 79-84. DOI

Davis, M. H. (1980). A multidimensional approach to individual differences in empathy. JSAS Catalog of Selected Documents in Psychology, 10, 85.

Dunbar, R. \& Shultz, S. (2007). Evolution in the Social Brain. Science, 317 (5843), 1344-1347. DOI

Eibl-Eibesfeldt, I. (1979). Human ethology: concepts and implications for the sciences of man. Behavioral and Brain Sciences, 2(1), 1-26. DOI

Feather, N., \& Nairn, K. (2005). Resentment, envy, schadenfreude, and sympathy: Effects of own and other's deserved or undeserved status. Australian Journal of Psychology, 57(2), 87102. DOI 
Fernández, A., Dufey, M. \& Kramp, U. (2011). Testing the Psychometric Properties of the Interpersonal Reactivity Index (IRI) in Chile. European Journal of Psychological Assessment, 27(3), 179-185. DOI

Greitemeyer, T., \& Sagioglou, C. (2017). The longitudinal relationship between everyday sadism and the amount of violent video game play. Personality and Individual Differences, 104, 238-242. DOI

Greitemeyer, T., Weiß, N. \& Heubergermes, T. (2018). Are everyday sadists specifically attracted to violent video games and do they emotionally benefit from playing those games? Aggressive Behavior. 2019;45:206-213. DOI

Jonason, P., Duineveld, J. \& Middleton, J. (2015). Pathology, pseudopathology, and the Dark Triad of personality. Personality and Individual Differences, 78, 43-47. DOI

Jones, D. \& Paulhus, D. (2011). The role of impulsivity in the Dark Triad of personality. Personality and Individual Differences, 51(5), 679-682. DOI

Jones, D. \& Paulhus, D. (2014). Introducing the Short Dark Triad (SD3): A Brief Measure of Dark Personality Traits. Assessment, 21(1), 28-41. DOI

Kircaburun, K., Alhabash, S., Tosuntaş, Ş.B. \& Griffiths, M. (2018).Uses and Gratifications of Problematic Social Media Use Among University Students: a Simultaneous Examination of the Big Five of Personality Traits, Social Media Platforms, and Social Media Use Motive. Int JMent Health Addiction, 1-23. DOI

Kircaburun, K., Demetrovics, Z. \& Tosuntaş, Ş.B. (2018). Analyzing the Links Between Problematic Social Media Use, Dark Triad Traits, and Self-esteem. International Journal of Mental Health and Addiction, 1- 12. DOI

Klimovsky, G. (1997). Las desventuras del conocimiento científico: una introducción a la epistemología [The misadventures of scientific knowledge: en epistemological introduction]. Buenos Aires: A-Z Editora

Krems, J. A. (2018). Friendship Jealousy": An (Overlooked) Emotion for Friendship Maintenance? A Dissertation Presented in Partial Fulfillment of the Requirements for the Degree Doctor of Philosophy, Arizona State University.

Lambe, L. J., Cioppa, V. D., Hong, I. K., \& Craig, W. M. (2018). Standing up to bullying: A social ecological review of peer defending in offline and online contexts. Aggression and Violent Behavior. DOI

Muñiz, J., Elosua, P., y Hambleton, R.K. (2013). Directrices para la traducción y adaptación de los tests: segunda edición [Directions for the translation and adaptation of tests: second edition]. Psicothema, 25, 151-157. DOI

Paulhus, D. L., \& Dutton, D. G. (2016). Everyday sadism. In V. Zeigler-Hill \& D. K. Marcus (Eds.), The dark side of personality (pp. 109-120). Washington, D.C.: American Psychological Association Press.

Paulhus, D. \& Williams, K. (2002). The Dark Triad of personality: Narcissism, Machiavellianism, and psychopathy". Journal of Research in Personality, 36(6), 556-563. DOI

Porter, S. \& Woodworth, M. (2006). Psychopathy and aggression. En Patrick, C. (Ed.), Handbook of psychopathy (pp. 481-494). New York: Guilford Press

Tooby, J., \& Cosmides, L. (1996). Friendship and the banker's paradox: Other pathways to the evolution of adaptations for altruism. In W. G. Runciman, J. M. Smith, \& R. I. M. Dunbar (Eds.), Proceedings of The British Academy, ol. 88. Evolution of social behaviour patterns in primates and man (pp. 119-143). New York, NY, US: Oxford University Press.

Sherman, L. E., Hernandez, L. M., Greenfield, P. M., \& Dapretto, M. (2018). What the brain "Likes": neural correlates of providing feedback on social media. Social Cognitive and Affective Neuroscience, 13(7), 699-707. DOI 
Smith, R., Powell, C., Combs, D. \& Schurtz, D. (2009). Exploring the When and Why of Schadenfreude. Social and Personality Psychology Compass 3(4), 530 - 546. DOI

Suler, J. (2004). The Online Disinhibition Effect. Cyberpsychology \& Behavior, 7(3), 321-326. $\underline{\mathrm{DOI}}$

Van, Geel., Goemans, A., Toprak, F. \& Vedder, P. (2016). Which personality traits are related to traditional bullying and cyberbullying? A study with the Big Five, Dark Triad and sadism. Personality and Individual Differences, 106, 231-235. DOI

Wai, M., \& Tiliopoulos, N. (2012). The affective and cognitive empathic nature of the dark triad of personality. Personality and Individual Differences, 52(7), 794-799. DOI

Waytz, A., \& Gray, K. (2018). Does Online Technology Make Us More or Less Sociable? A Preliminary Review and Call for Research. Perspectives on Psychological Science, 13(4), 473491. DOI 